A nim. B ehav., 1995, 49, 911-929

\title{
The processing of spectral cues by the call analysis system of the túngara frog, Physalaemus pustulosus
}

\author{
WALTER WILCZYNSKI*†, A. STANLEY RAND \& \& MICHAEL J.RYAN†‡ \\ *D epartment of P sychology, The U niversity of T exas, A ustin, TX 78712, U.S.A. \\ †D epartment of Z oology, The U niversity of Texas, A ustin, TX 78712, U.S.A. \\ $¥$ Smithsonian Tropical Research Institute, Balboa, P anama
}

( Received 10 J anuary 1994; initial acceptance 25 J anuary 1994;

final acceptance 9 M arch 1994; M S. number: ${ }_{A 6672 R}$ )

\begin{abstract}
A bstract. How the $\mathrm{N}$ eotropical frog Physalaemus pustulosus uses spectral cues to recognize and assess the relative attractiveness of conspecific calls was examined using 50 different phonotaxis experiments with a total of 1005 individual female-choice tests. The advertisement call is an FM sweep from 900 to $430 \mathrm{~Hz}$, or 'whine', which can be followed by a 'chuck' (with most energy near $2500 \mathrm{~Hz}$ ) to enhance the whine's attractiveness. Female-choice tests pairing full whines against modified whines or chucks indicate that stimulation in a high-frequency region of the whine's fundamental between 900 and $560 \mathrm{~Hz}$, followed by stimulation in a partially overlapping low-frequency region between 640 and $500 \mathrm{~Hz}$ is necessary and sufficient for call recognition. No single frequency or frequency band within each region is crucial for recognition, and the recognition system is tolerant of silent gaps and shortening of the signal. A dding energy at any frequency in the normal whine's fundamental or in the chuck enhances the attractiveness of the call. The higher frequencies of the chuck, which contain $90 \%$ of its energy, are normally responsible for its enhancement of the call. These results suggest that much of the natural call in this species is unnecessary for call recognition, and that the recognition system is very tolerant of call variation. They also suggest that the system assessing the relative attractiveness of calls is extremely permissive, and that virtually anything that increases the amount of energy in the call at frequencies stimulating any part of the peripheral auditory system may make the call more attractive.
\end{abstract}

In many animal species, females use communication signals produced by males to discriminate conspecifics from heterospecifics and to choose among conspecific males for the purpose of mating. Interspecific and intraspecific mate choice are often treated as different, independent phenomena, and arguments about their evolution stress different selective consequences ( $R$ yan 1990a, b). $M$ echanisms for species recognition are often viewed as being very restrictive because of the potentially dire consequences of heterospecific matings (Dobzhansky 1937; Coyne \& Orr 1989). Sexual selection deriving from discrimination among conspecifics for potential mates is generally viewed as a less constrained and more unpredictable system ( $R$ and et al. 1992). Such intraspecific selection may lead to exaggeration or elaboration of traits in different ways, leading to the great divergence of communication signals among species (M ayr 1963; W est-E berhard 1983). This process is so permissive that female choice can be expressed for traits or adornments that are not naturally expressed by the conspecific males with which they normally breed (Burley 1985; R yan \& Wagner 1987; Christy 1988; Basolo 1990; R yan 1990a; Proctor 1991, 1993; R yan \& K eddyH ector 1992; R yan et al. 1992; Searcy 1992; R yan \& R and 1993a, b, c). R yan \& K eddy-H ector (1992) argue that, in general, signals that are more stimulatory are more attractive to females, and that there are multiple ways to achieve enhanced stimulation. If this is so, sexual selection derived from this mate choice could cause the conspecific recognition signal to be elaborated with stimuli that enhance its attractiveness, but that are not sufficient themselves for mate attraction.

In animal communication systems, species recognition and intraspecific mate choice are not as separate as their differing theoretical treatments might suggest (R yan \& R and 1993c). Often the same communication channel, for example, acoustic, carries the signals for both discriminations. The same or different parameters of a single signal, such as an advertisement or mating 
call, may provide information used to distinguish between heterospecifics and conspecifics, and to discriminate among conspecifics. Furthermore, the ultimate decision from both types of discrimination is the same: accepting or not accepting an individual as a mate. Littlejohn (1981, 1988) has argued that interspecific mate choice is simply an extension of intraspecific mate choice. It therefore remains an open question as to whether there are different rules for conspecific call recognition and for assessing the attractiveness of a recognized call, and how these processes interact to mediate the behavioural expression of mate choice.

One approach to defining how calls are recognized and assessed is to investigate an organism's responses to portions or variations of its communication signal. We have adopted this approach in studying the acoustic communication system of the túngara frog. This study is the first stage in examining how female túngara frogs use the constellation of spectral, temporal, and amplitude characteristics comprising the male advertisement call of this species to recognize a call as a conspecific signal and assess its attractiveness.

In this frog, as in most anurans (W ells 1977; Gerhardt 1988; R and 1988), males produce an advertisement call that attracts females. The $P$. pustulosus call is more complex than the calls of many anurans. $\mathrm{M}$ ales produce a frequency modulated (FM) 'whine' either alone or quickly followed by one to six short 'chucks' ( $R$ and \& R yan 1981; R yan 1985). In a typical call, the whine has a fundamental frequency that sweeps from 900 to $430 \mathrm{~Hz}$ in $300 \mathrm{~ms}$ and has several harmonics. M ost of the energy in the whine is in the fundamental. The chuck is much shorter (35 ms). It has a fundamental frequency of $\mathrm{ca} 215 \mathrm{~Hz}$ and 14 harmonics. N early all of the energy $(>90 \%)$ in the chuck lies in the harmonics above $1500 \mathrm{~Hz}$, and the average dominant frequency is $2500 \mathrm{~Hz}$ ( $\mathrm{R}$ yan 1985; Ryan \& R and 1990; Ryan et al. 1990). $\mathrm{F}$ emale-choice tests have shown that the whine is both necessary and sufficient for eliciting female phonotaxis and that the upper harmonics of the whine have no influence on this behaviour (R yan $\& R$ and 1990; $R$ and et al. 1992). M oreover, the frequency of the whine must sweep from high to low in order for the call to be recognized by a female (R yan 1983a) or a male (R ose et al. 1988; Zelick et al. 1991). The chuck alone does not attract females, but does enhance the attractive- ness of a call when it is added to a whine ( $R$ and \& Ryan 1981; Ryan \& R and 1990).

The response properties of the auditory system suggest that the whine and chuck are detected largely by separate peripheral auditory receptor organs (R yan et al. 1990). A nurans have two such organs in the inner ear, the amphibian papilla and the basilar papilla, tuned to largely separate low $(<1200 \mathrm{~Hz})$ and high (for small frogs like P. pustulosus often above $2000 \mathrm{~Hz}$ ) frequency bands (Wilczynski \& Capranica 1984; Zakon \& Wilczynski 1988; Wilczysnki 1992). The amphibian papilla contains an array of tonotopically organized hair cells (Lewis \& Lombard 1988), each most sensitive to a different frequency (its best excitatory frequency), while the basilar papilla contains many fewer hair cells all tuned to similar frequencies. Electrophysiological recordings in the midbrain of $P$. pustulosus reveal amphibian papilla tuning to be from approximately 100 to $1200 \mathrm{~Hz}$, with a peak sensitivity averaging $500 \mathrm{~Hz}$, and basilar papilla tuning centred at $2100 \mathrm{~Hz}$ (R yan et al. 1990). This indicates that the whine, which is necessary for species recognition, stimulates the amphibian papilla, and that the salient portion of the natural chuck, which makes a recognized call more attractive, mostly stimulates the basilar papilla.

$\mathrm{H}$ ere we report on a series of experiments that systematically dissect and manipulate the whine and chuck portions of the call and assess their abilities to elicit female phonotaxis. These be havioural data are used to construct a simple model of how the nervous system recognizes and interprets the spectral features of the complex advertisement call of $P$. pustulosus to arrive at a mate-choice decision.

\section{GENERAL METHODS}

F or each of the experiments detailed below, we collected gravid female $P$. pustulosus in amplexus in and around $\mathrm{G}$ amboa, R epublic of Panama, and transported them to an indoor test chamber for two-choice phonotaxis tests. These tests were conducted from 1990 to 1993 as in Ryan \& R and (1990). We synthesized calls on an A miga computer (model 2000) using software developed by J. Schwartz. Each call of a stimulus pair was played through one of the channels of the computer to an ADS L 200C speaker. Speakers were 

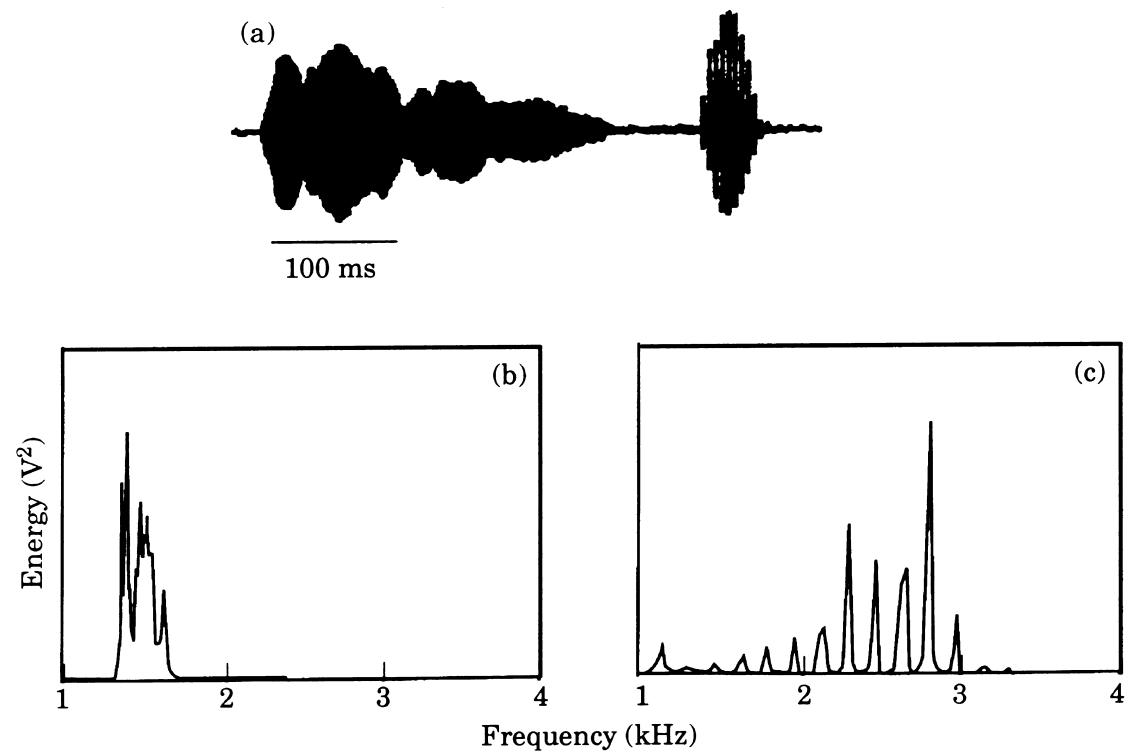

Figure 1. Illustration of features of the whine and chuck recorded at the female release point in the phonotaxis test chamber. (a) Oscillogram of whine fundamental followed by a chuck. F ourier transforms of the whine (b) and chuck (c) showing the distributions of energy as a function of frequency for the two parts of the call.

placed directly opposite each other, $3 \mathrm{~m}$ apart, in a small room. The room had a cement floor and its walls were covered with foam to reduce reverberation. Test stimuli recorded at the centre of the arena revealed only slight degradation (Fig. 1). Test stimuli consisted of synthesized call variants paired against a synthesized version of the fundamental of a natural whine, or noise with a duration and amplitude envelope of a natural whine. Stimuli were broadcast at a peak intensity of $82 \mathrm{~dB}$ SPL (re: $20 \mu \mathrm{Pa}$ ) at the site of the female, with the calls in the test pair presented antiphonally, each call at a rate of one call per $2 \mathrm{~s}$, for the duration of the trial. We placed the female equidistant between the speakers under a small, inverted funnel. A fter 2 min of stimulus presentation, we released the female while stimulus presentation continued. If the female remained motionless for 5 min after release, or at any time during the trial, the trial was terminated and scored as a 'no response'. If the female moved about the test chamber, the trial continued for $15 \mathrm{~min}$ or until a female approached within $10 \mathrm{~cm}$ of a speaker. A $n$ approach to within $10 \mathrm{~cm}$ of a speaker was scored as a choice for that stimulus, while a lack of such an approach after 15 min was scored as a 'no response'. We tested most females with six to nine different stimulus pairs, presented mostly as sequential tests separated by several minutes on the night they were collected, but no female was tested more than once with any one stimulus pair. Statistical analysis of the phonotaxis results was by exact binomial probability test using a two-tailed test unless a priori predictions could be made, in which case a one-tailed test was used.

A significant preference for a call variant would demonstrate that this stimulus is sufficient for eliciting female phonotaxis. However, a lack of phonotaxis could result either from females being unresponsive to any stimulation, for example due to lack of motivation, or because neither test stimulus was biologically meaningful. Therefore, we used only females that had first responded to a conspecific call in a previous test in the call variant versus noise experiments. In addition, if a female did not respond to either the call variant or the noise, her data were discarded unless she then showed a phonotactic response in a subsequent test with a different stimulus pair. We feel such a procedure ensures that we only included females whose lack of response was more likely to be caused by a lack of appropriate acoustic stimuli rather than a lack of motivation.

The null hypothesis was determined by $\mathrm{R}$ and et al. (1992). They presented 20 females with two 
speakers located in their normal positions in the test chamber. One speaker broadcast noise with the duration and amplitude envelope of a natural whine. The other was silent. The number of times a female approaches the silent speaker estimates the number of times that a female would happen to approach a speaker by random chance without reference to the stimulus being broadcast. Eighteen females showed no response (as defined above) and two came into contact with the silent speaker. Thus, if females ignore the call variant as a communication signal, the null expectation is that they would still approach the speaker broadcasting it by chance in the ratio $2: 18$. We compared this expectation to the actual responses with a Fisher's exact test.

Test stimuli consisted of a synthetic whine and a synthetic chuck. The whine was an exponential frequency sweep moving from 900 to $430 \mathrm{~Hz}$ in $300 \mathrm{~ms}$ and was constructed with the envelope and time course of the fundamental FM sweep of the natural P. pustulosus call. The chuck was a 35-ms signal consisting of a harmonic series with a fundamental frequency of $215 \mathrm{~Hz}$ and a total of 14 harmonics yielding an uppermost harmonic at $3010 \mathrm{~Hz}$. The energy distribution of a natural chuck was reproduced in the synthetic chuck. Sound synthesis software allowed us to edit out portions of either the whine or chuck to construct stimuli with silent 'gaps', or present only portions of each. We also synthesized white noise bursts, tone bursts, or tone combinations for presentation alone or in combination with the whine.

Three studies were undertaken. The first examined responses to variants of the normal whine; the second examined phonotaxis to tonal stimuli; and the third examined preferences for variations of the chuck. These are discussed separately below. Together these studies consisted of 1005 individual female-choice tests between 50 different stimulus pairs (excluding those tests in which females made no responses in pre- and post-test situations as described above).

\section{PHONOTAXIS TO WHINE VARIANTS}

The fundamental of a natural whine is a frequency modulated (F M ) signal that sweeps from 900 to $430 \mathrm{~Hz}$, stimulating a series of tonotopically organized receptors on the amphibian papilla. In principle, the F M sweep could represent a mechanism for enabling three types of call detection, which in their strongest and simplest forms are as follows. (1) All receptors within the frequency range of the call must be stimulated in order from high to low. (2) There are two specific receptors at two specific frequencies that must be stimulated in a specific temporal sequence; the frequency sweep is merely a mechanism to ensure both receptors are stimulated with a specific time relationship and stimulation of other receptors is superfluous for call recognition. (3) A highfrequency portion of the A P must be stimulated, followed by a low-frequency portion, but there is no one receptor in either portion that is critical for call recognition; the high and low portions of the amphibian papilla can be either (a) completely separate or (b) overlapping to some degree.

\section{M ethods}

To confirm that the direction of the F M sweep in the call is important for recognition, we constructed a synthetic call that reversed the fre quency sequence while maintaining the natural envelope and duration of the call. We then paired this reverse whine against the noise burst with the same duration and envelope as a natural whine in a choice test to determine whether the reverse whine could elicit phonotaxis.

To assess the importance of different regions of a natural whine for call recognition, we constructed a series of whine variants by digitally zeroing the amplitude in the synthetic whine in different time segments. Boundaries for the variants tested were: $0 \mathrm{~ms}, 900 \mathrm{~Hz} ; 50 \mathrm{~ms}, 680 \mathrm{~Hz}$; $63 \mathrm{~ms}, 670 \mathrm{~Hz} ; 74 \mathrm{~ms}, 640 \mathrm{~Hz} ; 100 \mathrm{~ms}, 560 \mathrm{~Hz}$; $110 \mathrm{~ms}, 520 \mathrm{~Hz} ; 150 \mathrm{~ms}, 500 \mathrm{~Hz} ; 264 \mathrm{~ms}, 430 \mathrm{~Hz}$; $314 \mathrm{~ms}, 430 \mathrm{~Hz}$. The $0-$ and 314-ms boundaries represent the beginning and end of the whine. Stimulus boundaries are illustrated in Fig. 2. Whine variants included truncated whines and whines with silent gaps. We gave females a choice between a whine variant and a noise burst of the same duration and envelope as the full natural whine to determine whether the whine variant was sufficient to elicit phonotaxis. In a second set of tests, we gave females a choice between a whine variant and the full synthetic whine to determine whether the whine variant was as attractive to females as the natural whine. 


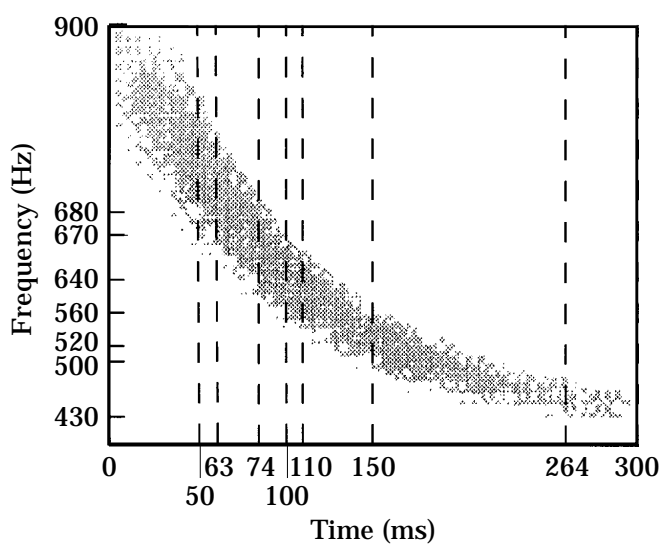

Figure 2. Diagram of the whine fundamental of a $P$. pustulosus advertisement call. D ashed lines indicate boundaries at which the various portions of the whine were removed in making stimuli for the female choice tests. See text for full descriptions of test stimuli.

\section{Results}

Females did not display phonotaxis to the reverse whine. The ratio of females approaching the speaker broadcasting the reverse whine was $1: 19$, which was not significantly different from the null hypothesis of 2:18 $(P=1 \cdot 00)$.

R esults for the tests with whine variants are shown in Table I. M any whine variants were adequate to elicit phonotaxis when paired against the noise stimulus (Fig. 3), including whines lacking the first $50 \mathrm{~ms}$ or last $214 \mathrm{~ms}$ of the normal whine, as well as any whine variant that deleted no more than $50 \mathrm{~ms}$ of the whine regardless of the position of those $50 \mathrm{~ms}$. Whine variants consisting only of the segment from 50 to $150 \mathrm{~ms}$ did elicit phonotaxis. However, any variant that deleted this entire segment did not, although up to $50 \mathrm{~ms}$ of the $50-150$-ms segment could be deleted as long as $50 \mathrm{~ms}$ of the whine preceded the deletion.

Tests pairing whine variants against the full whine fundamental showed that females preferred the full whine to nearly all the variants (Table I). One exception was the variant in which the tailing segment of the whine from 264 to 314 ms was deleted. In that comparison, there was a nonsignificant trend $(P=0.08)$ to prefer the full whine. This exception might be because the tailing portion of the whine contains only $2 \%$ of the energy of the full whine, so deleting it represents only a very small change in total energy. The other exception was one in which only $20 \mathrm{~ms}$ of the whine from 40 to $60 \mathrm{~ms}$ was deleted. Here too there was a non-significant tendency toward preferring the full whine $(P=0 \cdot 13)$, again probably indicating that deleting only $20 \mathrm{~ms}$ of the signal was too small a change to be readily noticeable to all females. In no case did a frog prefer a whine variant to a full whine.

\section{C onclusions}

As indicated previously (R yan 1983a), females do not recognize a reverse whine as a conspecific call. Thus, call recognition does not occur if low-frequency amphibian papilla stimulation precedes high-frequency stimulation.

The results from tests pairing whine variants against noise allow us to reject two possibilities for the significance of the FM sweep in call recognition. Because portions of the whine could be deleted and still yield a sufficient stimulus for female phonotaxis, we can reject the hypothesis that all receptors in the $900-430 \mathrm{~Hz}$ region of the amphibian papilla must be stimulated for the call to be recognized; thus much of the call is unnecessary for recognition. G erhardt (1988) has reviewed results in other anurans showing that many features can be eliminated from calls while preserving their ability to elicit female phonotaxis. F urthermore, because $50 \mathrm{~ms}$ deletions could be made anywhere in the whine and still yield a sufficient stimulus, we can reject the hypothesis that there are two specific frequencies that must be stimulated for call recognition to occur. R ather, there seem to be two regions of the amphibian papilla, a high-frequency region and a lowfrequency region, that must be stimulated in order for call recognition to occur. Stimulation anywhere within those respective frequency regions is sufficient to elicit phonotaxis.

Examination of the responses to the whine variants suggests the boundaries of the high and low regions and indicates a frequency region in which they overlap. The high-frequency region extends at least from 900 to $560 \mathrm{~Hz}$, the region stimulated by the first $100 \mathrm{~ms}$ of the sweep. Tests with pure-tone stimulation (see below) suggest that this high-frequency region might extend down to $500 \mathrm{~Hz}$. The low-frequency region extends at least from 640 to $500 \mathrm{~Hz}$, the region stimulated by the sweep from 75 to $150 \mathrm{~ms}$. Thus 
Table I. R esults of phonotaxis tests pairing modified whines against either noise or the fundamental of a natural whine

\begin{tabular}{|c|c|c|c|c|c|c|c|}
\hline \multicolumn{2}{|c|}{ Whine variant $(A)$} & \multirow{2}{*}{$\begin{array}{c}\text { A lternate } \\
\text { stimulus (B) }\end{array}$} & \multicolumn{4}{|c|}{$\mathrm{N}$ umber of females } & \multirow[b]{2}{*}{$P$} \\
\hline G ap (ms) & Segment (ms) & & A & NR & $B$ & Total & \\
\hline Complete & None & N oise & 2 & 17 & 1 & 20 & $\mathrm{~N}$ ull hypothesis \\
\hline None & $0-314$ & N oise & 20 & 0 & 0 & 20 & $0.000^{*}$ \\
\hline $0-50$ & $50-314$ & N oise & 15 & 5 & 0 & 20 & $0.000 *$ \\
\hline $0-63$ & $63-314$ & N oise & 14 & 7 & 0 & 21 & $0.000 *$ \\
\hline $0-76$ & $76-314$ & N oise & 8 & 12 & 0 & 20 & $0.030 *$ \\
\hline $0-88$ & 88-314 & N oise & 8 & 11 & 1 & 20 & $0.032 *$ \\
\hline $0-100$ & $100-314$ & N oise & 3 & 15 & 0 & 18 & 0.450 \\
\hline $40-60$ & $0-40,60-314$ & N oise & 17 & 2 & 1 & 20 & $0.000 *$ \\
\hline $50-100$ & $0-50,100-314$ & N oise & 20 & 0 & 0 & 20 & $0.000 *$ \\
\hline $50-150$ & $0-50,150-314$ & N oise & 6 & 14 & 0 & 20 & 0.120 \\
\hline $50-314$ & $0-50$ & N oise & 1 & 20 & 0 & 21 & 0.480 \\
\hline $63-314$ & $0-63$ & N oise & 1 & 19 & 0 & 20 & 0.500 \\
\hline 74-314 & $0-74$ & N oise & 7 & 14 & 0 & 21 & 0.075 \\
\hline $87-314$ & $0-87$ & N oise & 7 & 12 & 0 & 19 & 0.065 \\
\hline $90-110$ & $0-90,110-314$ & N oise & 14 & 8 & 0 & 22 & $0.000 *$ \\
\hline $100-150$ & $0-100,150-314$ & N oise & 17 & 3 & 0 & 20 & $0.000 *$ \\
\hline $100-314$ & $0-100$ & N oise & 15 & 5 & 0 & 20 & $0.000 *$ \\
\hline $264-314$ & $0-264$ & N oise & 16 & 5 & 0 & 21 & $0.000 *$ \\
\hline $0-50,100-314$ & $50-100$ & N oise & 4 & 21 & 0 & 25 & 0.430 \\
\hline $0-50,150-314$ & $50-150$ & N oise & 8 & 13 & 0 & 21 & $0.040 *$ \\
\hline $50-100,150-314$ & $0-50,100-150$ & N oise & 11 & 10 & 0 & 21 & $0.004 *$ \\
\hline $0-100$ & $\begin{array}{c}100-314 \\
\text { (increased amplitude) }\end{array}$ & N oise & 17 & 3 & 0 & 20 & $0.001 *$ \\
\hline None & $\begin{array}{c}680-560 \mathrm{~Hz} \\
\text { (100 ms duration) }\end{array}$ & N oise & 9 & 11 & 0 & 20 & $0.015^{*}$ \\
\hline None & R everse whine & N oise & 1 & 19 & 0 & 20 & 1.000 \\
\hline $0-50$ & $50-314$ & Whine & 2 & & 18 & 20 & $0.000 *$ \\
\hline $0-100$ & $100-314$ & Whine & 0 & & 20 & 20 & $0.000 *$ \\
\hline $40-60$ & $0-40,60-314$ & Whine & 7 & & 15 & 22 & 0.134 \\
\hline $50-100$ & $0-50,100-314$ & Whine & 0 & & 20 & 20 & $0.000 *$ \\
\hline $50-150$ & $0-50,150-314$ & Whine & 0 & & 20 & 20 & $0.000 *$ \\
\hline $90-110$ & $0-90,110-314$ & Whine & 2 & & 18 & 20 & $0.000 *$ \\
\hline $100-314$ & $0-100$ & Whine & 0 & & 22 & 22 & $0.000 *$ \\
\hline $150-314$ & $0-150$ & Whine & 0 & & 13 & 13 & $0.000 *$ \\
\hline $264-314$ & $0-264$ & Whine & 1 & & 8 & 9 & 0.080 \\
\hline $0-50,150-314$ & $50-150$ & Whine & 0 & & 20 & 20 & $0.000 *$ \\
\hline
\end{tabular}

See text and Fig. 1 for a more complete description of the stimuli. Gap: the portion of the normal whine missing (with 0 equal to the beginning and 314 ms indicating the end of the normal whine); segment: the portion presented to the female; noise: a noise burst with the duration of a normal whine; whine: the fundamental of a normal whine: $A$ : the number of females choosing the whine variant; N R : the number of no responses; $B$ : the number choosing the noise or full whine; total: the total choices for the test. $P$-values for noise tests are exact binomial probabilities combining N R and B and using 2:18 as the null hypothesis; for other tests a null probability of 0.5 is assumed. $*$ D enotes significant preference for one of the stimuli at $P<0.05$.

a variant that deletes the first $100 \mathrm{~ms}$ of the whine is not able to elicit phonotaxis, even though over two-thirds of the natural whine duration remains, because it stimulates the low-frequency region, but not the high. Conversely, variants that truncate the whine at 63 or $74 \mathrm{~ms}$ do not elicit phonotaxis because these stimulate only the high- frequency region, but not the low. A variant consisting only of the 50 -150 ms region is effective because it allows stimulation of both high and low regions, while a variant deleting this region is ineffective because it allows stimulation of the high region in the first $50 \mathrm{~ms}$, but not the critical low region from 75 to $150 \mathrm{~ms}$ even though 
frequencies below that zone remain in the call. The overlap region itself is not critical for stimulation, as whine variants deleting it, such as those deleting only the $50-100,100-150$, or $90-110 \mathrm{~ms}$ portions of the whine, are effective as long as some of the high- and low-frequency regions remain stimulated.

Using the envelope of the natural whine does present some problems in interpreting the potential effects of stimulation by the lower frequencies of the whine because there is so little energy there. Our results show that the portion of the whine after the first $100 \mathrm{~ms}$ is not sufficient to elicit phonotaxis. Perhaps this is because frequencies stimulated there are not able to act as the lowfrequency portion of the whine or because in a natural call there is too little energy at those frequencies. To partly resolve this, we constructed an artificial whine with a constant amplitude throughout. We then removed the first $100 \mathrm{~ms}$ and tested the remaining portion against the noise stimulus. U nlike the equivalent variant of the natural whine, this variant of the synthetic whine did elicit phonotaxis (17 choices for this stimulus versus 3 no responses, $P<0.001$ ). Clearly the later, lower-frequency portion of the natural whine could elicit phonotaxis if there were more energy in it. F urthermore, because this variant did support phonotaxis, the high-frequency portion of the call must reach as low as $560 \mathrm{~Hz}$, followed by stimulating some portion between 640 and $500 \mathrm{~Hz}$ (the frequency stimulated at the $100-\mathrm{ms}$ point of the whine), an interpretation supported by the results of single-tone experiments described below. The low-frequency portion may or may not extend to the end of the whine. Therefore, while we can identify the boundaries of the highand low-frequency portions of the natural whine, the exact boundaries of the high- and lowfrequency stimulation acceptable for call recognition in all circumstances can not be identified with certainty. The results do suggest, however, that high- and low-frequency portions exist in the analyser, that stimulation of any frequency within the zones is sufficient to trigger recognition of that portion, and, importantly, that the two zones overlap in the middle of the whine.

One whine variant also provides an indication of the minimum duration required for the whine to be recognized. The variant preserving only the 50-100-ms portion of the whine did not elicit phonotaxis even though it fell within the area where the high- and low-frequency regions overlap. This suggests that for the whine to be recognized as a conspecific call the frequency sweep must be at least $50 \mathrm{~ms}$ long in addition to stimulating the appropriate frequency regions from high to low. To test this possibility, we constructed a whine variant consisting of an $F M$ sweep with the same frequency range as the 50-100-ms portion of the whine, $680-560 \mathrm{~Hz}$, but with the duration being $100 \mathrm{~ms}$ rather than $50 \mathrm{~ms}$. When this whine variant was tested against the noise stimulus, it was effective in eliciting phonotaxis ( 9 versus 0 , with 11 'no response', $P=0.015$ ).

Although many whine variants were sufficient to elicit phonotaxis, none was as attractive as the full whine. The low-frequency portion of the natural whine following the initial $150 \mathrm{~ms}$ apparently cannot serve as the low-frequency portion of the call (the whine variant containing the 0-50 plus 150-314 ms portion of the whine does not elicit phonotaxis), but adding this portion makes the full whine more attractive than a variant without it. Similarly, a full whine is more attractive than a whine variant missing the highfrequency portion in the first $50 \mathrm{~ms}$ even though such a variant is sufficient to elicit phonotaxis. In short, stimulating some portion of the amphibian papilla between 900 and $560 \mathrm{~Hz}$, followed by stimulating some portion between 640 and $500 \mathrm{H} \mathrm{z}$ is necessary and sufficient to trigger phonotaxis in females, but adding additional amphibian papilla stimulation anywhere between 900 and $430 \mathrm{~Hz}$ makes the whine more attractive.

We did not determine whether amphibian papilla stimulation outside this frequency range can make the whine more attractive. $R$ and et al. (1992) did approach this problem by providing females with a choice between a full synthetic whine fundamental such as we used in our experiments and a whine fundamental plus the second and third harmonics normally found in a natural whine. They found that females did not discriminate between these stimuli. This result is puzzling because the upper harmonics contain energy in the basilar papilla range as well as the upper amphibian papilla range, and results below suggest that basilar papilla stimulation does enhance the attractiveness of a call, at least when that stimulation follows the whine (see also R and \& Ryan 1981; Ryan 1983b, 1985). At present we do not know why the upper harmonics do not influence phonotaxis. 

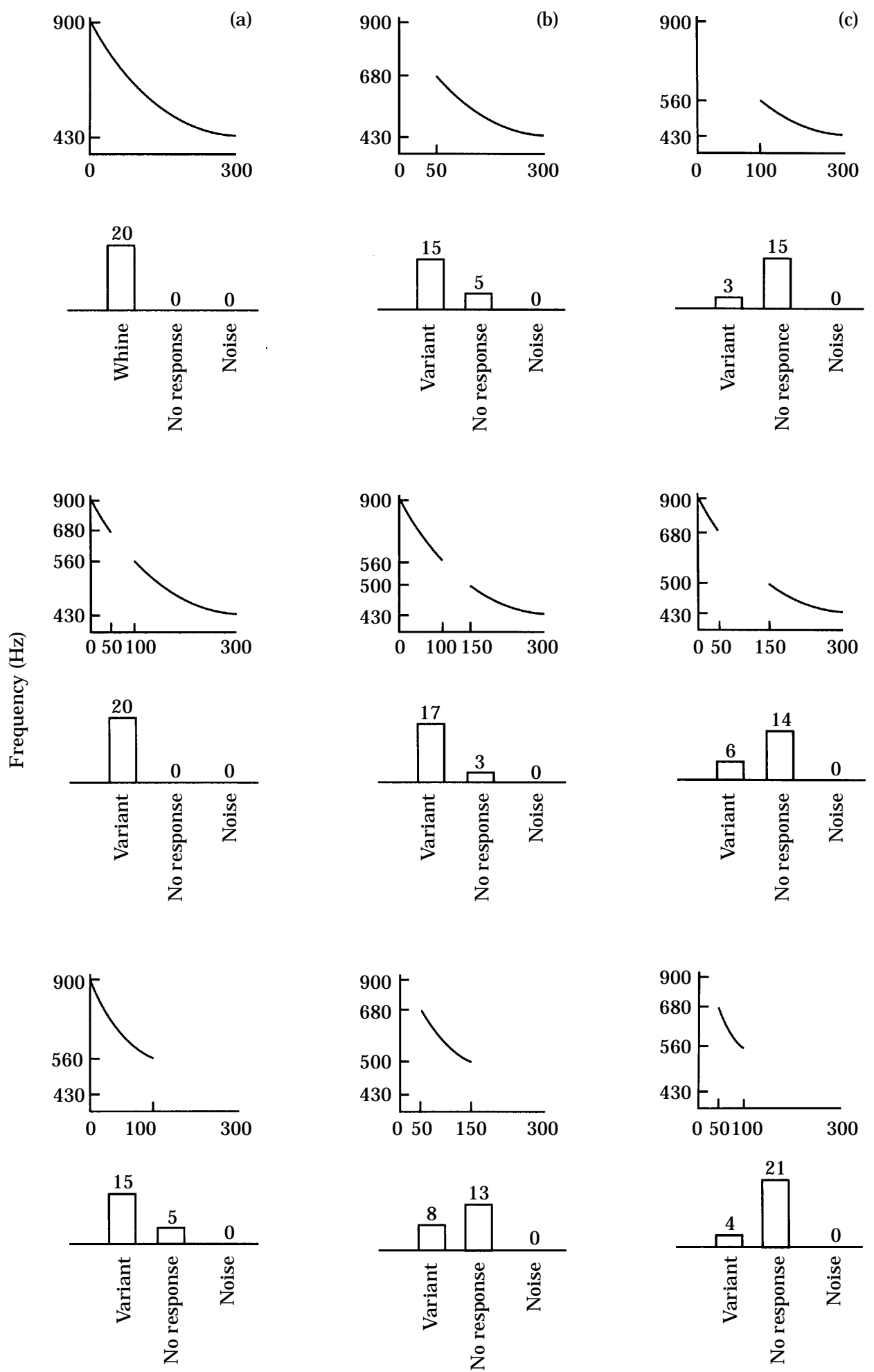


\section{PHONOTAXISTO TONES}

The previous experiment showed that stimulation anywhere in specific, partially overlapping highand low-frequency ranges was necessary and sufficient to elicit phonotaxis. To investigate further the rules for call recognition, we constructed a series of phonotaxis tests pairing single tones or tone combinations in different temporal relationships against the noise stimulus.

\section{M ethods}

We performed choice tests with the following stimuli. (1) Sequential two-tone combinations: the first tone, with a prescribed duration, was terminated at a zero crossing and followed immediately by the second tone, which was also terminated at a zero crossing. We then shaped the resultant two-tone sequence into the amplitude envelope of the full whine. Combinations tested against noise were $900 \mathrm{~Hz}$ for $150 \mathrm{~ms}$ followed by $430 \mathrm{~Hz}$ for $150 \mathrm{~ms} ; 430 \mathrm{~Hz}$ for $150 \mathrm{~ms}$ followed by $900 \mathrm{~Hz}$ for $150 \mathrm{~ms} ; 800 \mathrm{~Hz}$ for $100 \mathrm{~ms}$ followed by $500 \mathrm{~Hz}$ for $200 \mathrm{~ms} ; 500 \mathrm{~Hz}$ for $100 \mathrm{~ms}$ followed by $800 \mathrm{~Hz}$ for $200 \mathrm{~ms} ; 700 \mathrm{~Hz}$ for $100 \mathrm{~ms}$ followed by $550 \mathrm{~Hz}$ for $200 \mathrm{~ms}$. We also tested the $800+500 \mathrm{~Hz}$ combination against the full whine. (2) Simultaneous two-tone combinations: to determine whether the high-frequency tone must terminate before the low-frequency tone is recognized, we constructed stimuli in which two tones remained on for the 300-ms duration of the stimulus. The overall stimulus amplitude envelope was shaped like the full whine. The tone combinations were: $900+430 \mathrm{~Hz}$ and $800+500 \mathrm{~Hz}$. (3) Single tones: we determined whether single tones with frequencies near the start of the whine, near the end of the whine, and near the region where the critical high- and low-frequency zones overlap could support phonotaxis. Stimuli consisted of tones at 900,500 , or $430 \mathrm{~Hz}$ with a duration of $300 \mathrm{~ms}$ that were shaped into the amplitude envelope of the full whine.

\section{R esults}

The results are shown in Table II, with examples illustrated in Fig. 4. Of the sequential- tone combinations, $900+430 \mathrm{~Hz}, 430+900 \mathrm{~Hz}$ and $500+800 \mathrm{~Hz}$ did not elicit phonotaxis. The tone combinations of $800+500 \mathrm{~Hz}$ and $700+550 \mathrm{~Hz}$ did elicit phonotaxis. There was no significant difference in preference for the $800+500 \mathrm{~Hz}$ combination and a full whine. Tests with simultaneous tones were consistent with these results. The $900+430 \mathrm{~Hz}$ combination did not elicit phonotaxis, while the $800+500 \mathrm{~Hz}$ combination did. Only one single-tone stimulus elicited phonotaxis, the $500-\mathrm{Hz}$ tone; the $900-\mathrm{Hz}$ and $430-\mathrm{Hz}$ tones did not.

\section{C onclusions}

The results of the sequential-tone combinations are predicted from our interpretations of the whine-variant experiments and previous work on $P$. pustulosus call recognition (Ryan 1983a; R ose et al. 1988; Zelick et al. 1991). The $900+430 \mathrm{~Hz}$ and $430+900 \mathrm{~Hz}$ sequences should not have elicited phonotaxis because the whine-variant tests demonstrated that while $900 \mathrm{~Hz}$ appears to be within the high-frequency recognition zone, $430 \mathrm{~Hz}$ may be below the low-frequency recognition zone. In addition, the $430+900 \mathrm{~Hz}$ sequence presents the components in the incorrect order, as did the $500+800 \mathrm{~Hz}$ sequence. The fact that both the $800+500 \mathrm{~Hz}$ and $700+550 \mathrm{~Hz}$ combinations elicited phonotaxis shows first, that it is not necessary to stimulate multiple frequency bands in either the high- or low-frequency zone for the whine to be recognized and, second, that there is not any one particular frequency in either the high or low zone that must be stimulated for the whine to be recognized. Based on these results, we predict that any frequency in the high range, paired with any frequency in the low range, presented in the proper order and duration, should support female phonotaxis.

The lack of phonotaxis to the $900+430 \mathrm{~Hz}$ combination when the tones were presented simultaneously is predictable both from the whine variants and the two-tone sequence tests. The fact that the simultaneous presentation of $800+500 \mathrm{~Hz}$ elicited phonotaxis like the tones presented sequentially suggests that the call recognition

Figure 3. Illustrations of nine representative test stimuli and female responses to each when paired against the noise stimulus. Stimuli in columns (a) and (b) elicited phonotaxis significantly above the null hypothesis; stimuli in column (c) did not. See Table I for additional information, including P -values. 
Table II. R esults of phonotaxis tests with tone combinations

\begin{tabular}{|c|c|c|c|c|c|c|}
\hline \multirow{2}{*}{$\begin{array}{c}\text { Tone } \\
\text { combination (A) }\end{array}$} & \multirow{2}{*}{$\begin{array}{c}\text { A Iternate } \\
\text { stimulus (B) }\end{array}$} & \multicolumn{4}{|c|}{ N umber of females } & \multirow[b]{2}{*}{$P$} \\
\hline & & A & NR & B & Total & \\
\hline \multicolumn{7}{|l|}{ Sequential } \\
\hline $900+430$ & Noise & 6 & 13 & 1 & 20 & $0 \cdot 120$ \\
\hline $430+900$ & N oise & 2 & 18 & 0 & 20 & 0.700 \\
\hline $800+500$ & N oise & 20 & 3 & 0 & 23 & $0.000 *$ \\
\hline $500+800$ & Noise & 0 & 10 & 0 & 10 & 0.270 \\
\hline $700+550$ & N oise & 19 & 1 & 0 & 20 & $0.000 *$ \\
\hline $800+500$ & Full whine & 9 & 0 & 13 & 21 & 0.384 \\
\hline \multicolumn{7}{|l|}{ Simultaneous } \\
\hline $900+430$ & N oise & 4 & 15 & 1 & 20 & 0.330 \\
\hline $800+500$ & N oise & 8 & 14 & 0 & 22 & $0.048 *$ \\
\hline \multicolumn{7}{|l|}{ Single tone } \\
\hline 800 & N oise & 1 & 18 & 0 & 19 & 0.520 \\
\hline 500 & Noise & 10 & 10 & 0 & 20 & $0.007 *$ \\
\hline 430 & N oise & 0 & 19 & 1 & 20 & 0.540 \\
\hline
\end{tabular}

See Table I for explanation of abbreviations and text for descriptions of tone combination stimuli. A II tests are one-tailed as described for the noise tests in Table I. $* D$ enotes significant preference for the tone combination at $\mathrm{P}<0.05$.

system does not depend on the termination of the high-frequency stimulation for the low-frequency stimulation to be analysed, and further that processing the high-frequency stimulation does not interfere or mask processing of the low-frequency stimulation. This impression is strengthened by the results of the single-tone experiments. As expected, neither $900 \mathrm{~Hz}$ alone nor $430 \mathrm{~Hz}$ alone can elicit phonotaxis, as each stimulates only one frequency region. However, the $500-\mathrm{Hz}$ tone stimulates the amphibian papilla close to the region of overlap between these zones, and does elicit phonotaxis. A pparently, it can act as both a high- and a low-frequency tone, and serving as one does not interfere with it acting as the second.

Tests pairing whine variants against the full whine nearly always resulted in the full whine being more attractive. This would have led us to expect that a whine with only two frequencies should be less attractive than the full whine stimulating many frequencies. However, the $800+500 \mathrm{~Hz}$ tone combination and the full whine did not differ in attractiveness to females. One difference between the two-tone stimuli and the whine variants in experiment 1 is that there were no silent gaps in the two-tone stimulus and instead an extended, continual stimulation with the two tones. The fact that this is as attractive as a signal stimulating many different frequencies suggests that the call-enhancement system will accept increased stimulation resulting from activity at more receptors, or increased stimulation resulting from longer activity at few receptors. We presume that calls with increased amplitude at any or all frequencies would also be attractive, as these too would increase overall sensory stimulation.

\section{FREQUENCY CHARACTERISTICS OF THE CHUCK}

The chuck portion of the call follows the whine and makes the call more attractive to females, although alone it is not sufficient to trigger phonotaxis (R and \& Ryan 1981; Ryan 1983b, 1985). M ost of the chuck's energy lies in the upper harmonics, which are high enough in frequency to stimulate the basilar papilla (R yan et al. 1990). R yan \& R and (1990) found that synthetic chucks consisting of only the upper seven harmonics above $1500 \mathrm{~Hz}$, only the lower seven harmonics below $1500 \mathrm{~Hz}$, or a noise burst without harmonic structure were all equally able to enhance the attractiveness of the whine as long as they contained the same total amount of energy as the normal chuck. Therefore, the neural system responsible for processing acoustic adornments that make the call more attractive is quite 

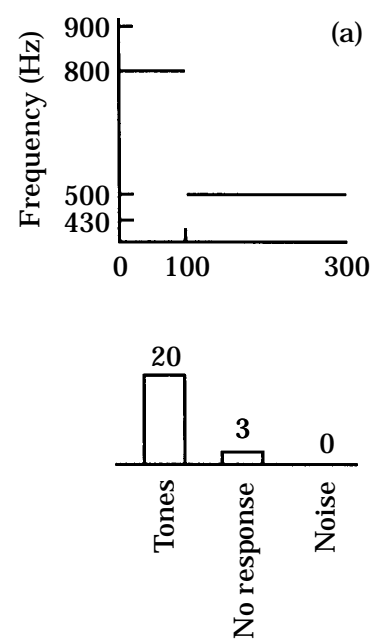
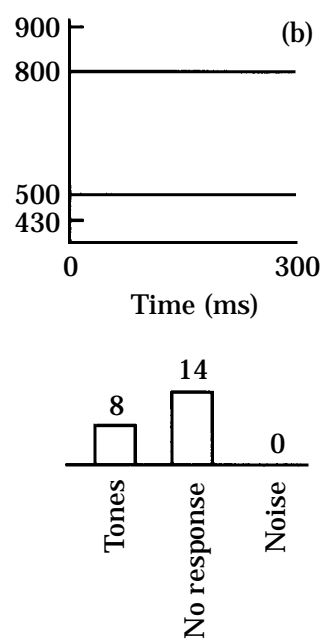
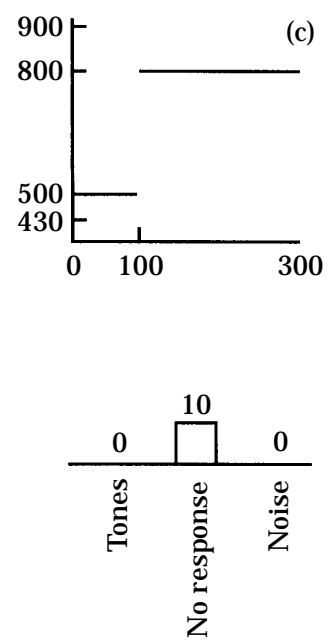

Figure 4. Illustrations of three tests using the $800-\mathrm{Hz}$ and $500-\mathrm{Hz}$ tone combinations and female responses to each. Sequentially presented $800 \mathrm{~Hz}+500 \mathrm{~Hz}$ (a) elicits phonotaxis; simultaneously presenting the same stimuli (b) still elicits phonotaxis significantly above the null hypothesis; sequentially presenting the same tones in reverse order (c) elicits no phonotaxis. See Table II for additional information.

permissive in terms of the spectral features of the chuck. This is in keeping with the results of tests with whine variants, which showed that adding energy anywhere in the frequency range of the fundamental of the whine made it more attractive than whine variants reduced to the necessary and sufficient stimulus conditions.

We extended this work to determine, first, how portions of the chuck with their natural energy distributions affected the attractiveness of the whine, and, second, whether single frequencies within the chuck were able to make a call more attractive. These manipulations are analogous to those we performed on the whine portions of the call; that is, presenting only portions of the natural stimulus or a spectrally impoverished version of the natural stimulus.

\section{$M$ ethods}

We constructed two chuck variants and appended them onto the end of a whine in the position normally occupied by a natural chuck. One variant was composed of the high-frequency half $(1500-3010 \mathrm{~Hz})$ of a natural chuck and one was composed of the low-frequency half (215$1500 \mathrm{~Hz}$ ) of a natural chuck. In a natural chuck, $90 \%$ of the energy is contained in the upperfrequency portion and $10 \%$ in the lower-frequency portion (see Fig. 1). To preserve the natural envelope of the half chucks, we constructed each chuck variant with the same duration and amplitude waveform as a natural chuck but scaled the amplitudes of the half-chucks to give the 90:10 high-to-low ratio as measured by an SPL meter at the site of the female in the test chamber. We tested each whine-plus-chuck variant against the whine alone.

In a second set of experiments, we paired a single tone at $2100 \mathrm{~Hz}$ having the duration and waveform of the natural chuck with a normal whine and tested this combination against the whine alone or the whine paired with a single tone at $3000 \mathrm{~Hz}$ with the same duration and amplitude. The first test was intended to determine whether, as for the whine, a single tone that naturally occurs in the signal (the chuck) could perform the same function (making the whine more attractive) as the whole signal, while the second test was intended to determine whether the position of the tone relative to the tuning of the basilar papilla influenced the preference expressed by the female. The basilar papilla is tuned on average to $2100 \mathrm{~Hz}$ in this population of $P$. pustulosus ( $R$ yan et al. 1990).

We also determined whether variation in the dominant frequency of a full-spectrum chuck influenced female phonotaxis to parallel the 
Table III. R esults of phonotaxis tests with chuck variants

\begin{tabular}{|c|c|c|c|c|c|}
\hline \multirow{2}{*}{$\begin{array}{c}\text { Chuck } \\
\text { variant }(A)\end{array}$} & \multirow[b]{2}{*}{ A Iternate stimulus (B) } & \multicolumn{3}{|c|}{ N umber of females } & \multirow[b]{2}{*}{$P$} \\
\hline & & A & B & Total & \\
\hline Whine+high half chuck & Whine & 15 & 6 & 21 & $0.034 *$ \\
\hline Whine+low half chuck & Whine & 12 & 9 & 21 & 0.664 \\
\hline Whine $+2100 \mathrm{~Hz}$ & Whine & 19 & 4 & 23 & $0.002 *$ \\
\hline Whine $+2100 \mathrm{~Hz}$ & Whine $+3000 \mathrm{~Hz}$ & 19 & 11 & 30 & $0 \cdot 100$ \\
\hline W hine $+2100 \mathrm{~Hz}$ & Whine $+3000 \mathrm{~Hz}$ & & & & \\
\hline full chuck & full chuck & 14 & 6 & 20 & 0.130 \\
\hline
\end{tabular}

See Table I for explanation of abbreviations and text for descriptions of stimuli. $\mathrm{P}$-values (one-tailed tests) were determined using exact binomial probabilities with the null hypothesis being no preference for either stimulus (i.e. a probability of 0.5 for each).

*D enotes significant preference for the whine plus chuck variant at $\mathrm{P}<0 \cdot 05$.

experiments using pure tones. This experiment was necessary because earlier studies ( $R$ yan 1980 , $1983 \mathrm{~b})$ that varied the chuck's fundamental frequency did not accurately reconstruct the amplitude relationships of the chuck's harmonics for technical reasons. The synthetic chucks in those studies approximated $90 \%$ of the energy in frequencies below $1500 \mathrm{~Hz}$, while in the natural call, $90 \%$ of the energy is in frequencies above $1500 \mathrm{~Hz}$. The synthetic chucks used in this experiment were constructed following the harmonic/amplitude relationships as in R yan \& R and (1990), which preserved the low:high frequency amplitude ratio seen in natural calls (Fig. 1). The dominant frequencies of the two synthetic chucks were 2100 and $3000 \mathrm{~Hz}$. These frequencies are within the natural range of call variation in $P$. pustulosus ( $R$ yan 1985).

\section{R esults}

R esults are shown in Table III. W ith the natural energy distribution preserved in the stimuli, females preferred a call with a whine plus a high half chuck to a whine alone. However, there was no significant preference for the whine plus lowhalf chuck over the whine alone. F urthermore, a whine coupled with a $2100-\mathrm{H}$ z tone was preferred over a whine alone and there was a strong trend $(P=0 \cdot 10)$ suggesting a preference for the $2100-\mathrm{H} \mathrm{z}$ tone over the $3000-\mathrm{Hz}$ tone. The responses to full-spectrum chucks with dominant frequencies of 2100 and $3000 \mathrm{~Hz}$ were not significantly different $(P=0 \cdot 13)$, although again there was a trend suggesting a preference for the lower dominantfrequency signal.

\section{Conclusions}

As with the whine, the entire chuck is not necessary to enhance the attractiveneness of the call. Either the upper half frequency of the chuck or a single frequency within that upper half will make a call more attractive. These results suggest that any stimulation of the basilar papilla will make the whine, which only stimulates the amphibian papilla, more attractive. F urthermore, the trends suggesting both that a $2100-\mathrm{Hz}$ tone is more attractive than a $3000-\mathrm{Hz}$ tone, and a full-spectrum chuck with a dominant frequency of $2100 \mathrm{~Hz}$ is more attractive than one with a dominant frequency of $3000 \mathrm{~Hz}$, suggest that a stimulus closer to the most sensitive region of the basilar papilla is more attractive. This is not to argue that a specific frequency is necessarily perceived as more attractive than another, but rather, the more stimulated the basilar papilla, the more attractive the call becomes (see also R yan 1985; R yan et al. 1990, 1992). This is reminiscent of the results with the whine variants showing that the greater the stimulation of the peripheral auditory system the more attractive the call.

These results support the interpretation of $R$ yan $(1980,1983 b, 1985)$ that variation in chuck frequency influences female phonotaxis, although we feel that the current support for this hypothesis is weaker than originally argued. As pointed out, however, the energy in the chucks used in the 
previous studies was unnaturally biased towards frequencies in the amphibian papilla region. In retrospect, this is an interesting result given that the low half chuck $(<1500 \mathrm{~Hz}$ ) can trigger phonotaxis if it contains sufficient energy ( $R$ yan $\& R$ and 1990). Thus, not only can we conclude that the amphibian papilla has the capacity to process a chuck ( $R$ yan \& R and 1990), we must also reinterpret R yan's earlier studies (1980, 1983b) as showing that frequency variation in the chuck within the amphibian papilla region could influence female phonotaxis as long as enough energy is contained in those lower frequencies. In summary, the experiments presented here indicate a trend for variation in a natural chuck's dominant frequency influencing female phonotaxis, and earlier studies indicate the same phenomenon could occur even if the energy in the chuck were biased towards lower frequencies.

The results also show that in a normal chuck, given the average amounts of energy in the high and low portions of the chuck, it is the high portion that is sufficient for the chuck's role in making a call attractive. Therefore, the basilar papilla plays the more important role in processing the natural chuck. The results suggest further that the harmonic structure of the chuck is not a necessary cue for making the call more attractive. The preference for the low tone over the high tone was almost identical to the preference for the full-spectrum chuck with the low dominant frequency over that with the high dominant frequency. Similarly, a noise burst in the position of a chuck also makes the call more attractive ( $R$ yan $\&$ R and 1990). The harmonic structure, including possibly those harmonics constituting the lower frequency half of the call, might therefore be more a reflection of vocal mechanics than the requirements of the receiving system.

\section{GENERAL DISCUSSION}

The whine-chuck advertisement call of $P$. pustulosus is a complicated acoustic signal that carries information important both for interspecific call recognition and intraspecific call assessment. Our behaviour tests provide some insight into the rules by which mate choice decisions are made. We have simplified the presentation of our results by assuming that call analysis has two parts, one for call recognition (mediating interspecific mate choice) and one for call assessment (mediating intraspecific mate preference). We caution that while our results suggest some differences in the type of spectral information each process uses, they do not prove a separation of recognition and assessment. O ur model for call analysis is shown in Fig. 5.

This decision model is based on previously published female-choice tests (Ryan 1983a, b, 1985; R yan \& R and 1990; R and et al. 1992) and on the data we report here. The frequency ranges of the amphibian and basilar papillae are deduced from our previous neurophysiological study of auditory tuning in this species (R yan et al. 1990). The results indicate that the whine is necessary and sufficient for call recognition and that the fundamental of the whine stimulates the amphibian papilla. Moreover, the FM sweep of the whine cannot go from low frequency to high; high-frequency amphibian papilla stimulation must occur at the beginning of the call. O ur results show that for the natural whine, stimulation of the amphibian papilla region from 900 to $500 \mathrm{~Hz}$ is critical for call recognition. This portion of the amphibian papilla is stimulated during the initial 150 ms of the whine. F urthermore, the tests with whine variants show that stimulating the amphibian papilla frequency region between 900 and $560 \mathrm{~Hz}$ (corresponding to the time $0-100 \mathrm{~ms}$ of the whine) indicates to the neural decision-making system that the high-frequency portion of the whine has occurred, and stimulating the amphibian papilla frequency region between 640 and $500 \mathrm{~Hz}$ indicates that the low-frequency portion of the whine has occurred. Stimulating any point within these respective regions is sufficient to indicate that a high or low part of the whine has occurred, as whine variants eliminating any $50-\mathrm{ms}$ part of these ranges still elicit phonotaxis as long as at least part of the high and low regions remain. $\mathrm{F}$ urthermore, the two-tone experiments show that stimulation at only two single frequencies within these regions, rather than at multiple points, is sufficient.

O ur results suggest that the duration of the $F M$ sweep must be at least 50 ms to be recognized. A whine variant encompassing the two frequency zones but lasting only $50 \mathrm{~ms}$ will not trigger phonotaxis, while a variant that spans the same frequencies but is stretched to $100 \mathrm{~ms}$ will. F urthermore, high-frequency amphibian papilla stimulation must occur at the beginning of the 
(b)

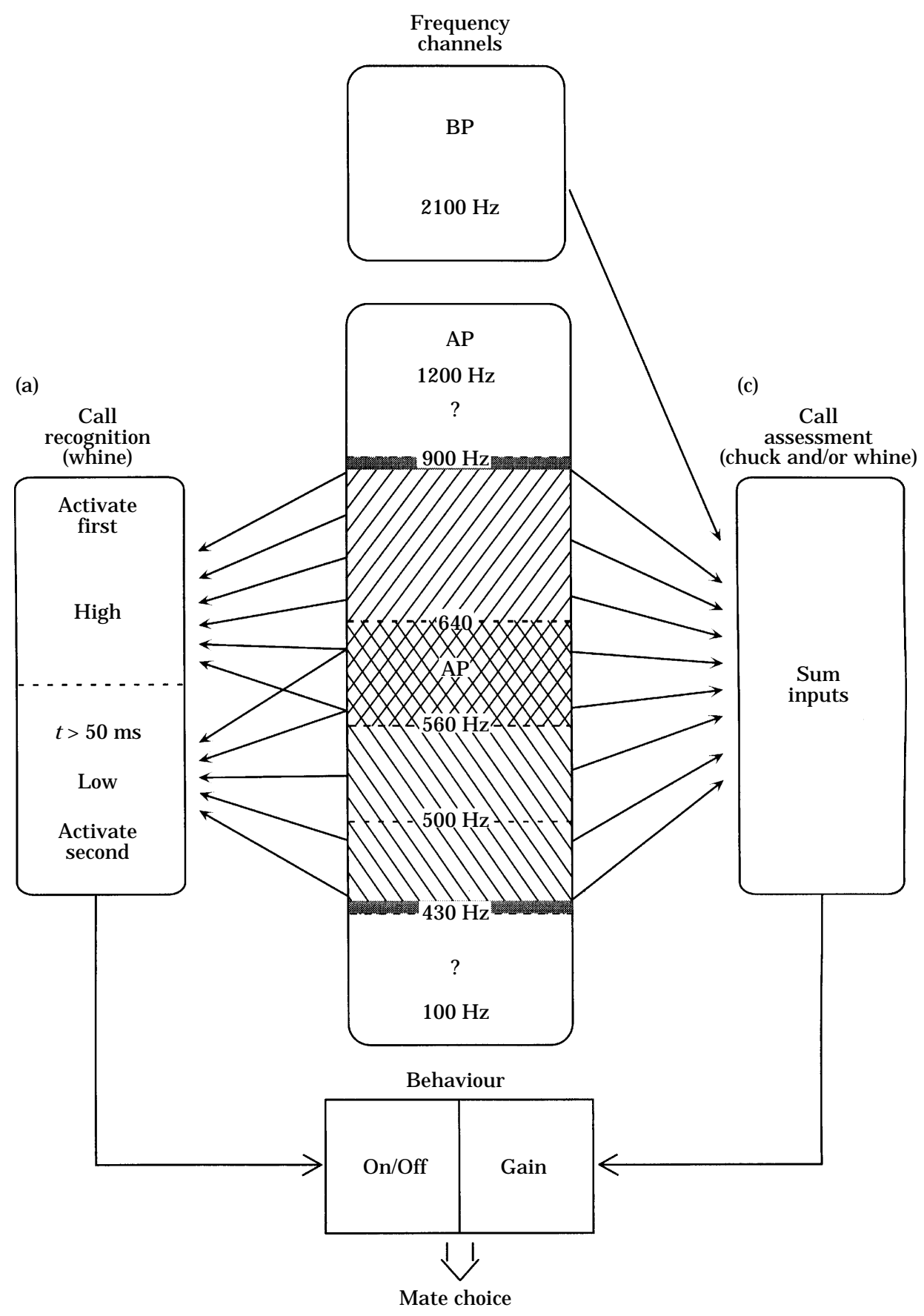


call. Beyond these minimal requirements, we did not identify any other temporal feature that must be met for call recognition to occur. In fact, two simultaneous tones elicit phonotaxis as well as two sequential tones of the proper frequency. This latter observation is particularly important in that it demonstrates that the neural analyser does not wait for the offset of the high-frequency stimulation to assess the presence of the low-frequency stimulation. In addition, the fact that a single tone close to the frequency at which the high and low regions overlap will trigger phonotaxis enhances the impression that the high- and low-frequency assessment occurs independently. Our hypothesis is that the neural analyser for call recognition is triggered by the presence of stimulation anywhere in the high-frequency amphibian papilla region, waits for a time ( $t>50 \mathrm{~ms}$ from high-frequency onset), then assesses the presence of stimulation anywhere in the low-frequency region. If this low-frequency stimulation is then present, the signal is recognized as a conspecific whine and phonotaxis is enabled. F uture tests are planned to determine whether there are additional restrictions on the temporal characteristics of the highand low-frequency stimulation or the time gap between them.

R yan (1983b, 1985) showed previously that the chuck portion of the call, which stimulates the basilar papilla, enhanced the attractiveness of the call, but was not sufficient to elicit phonotaxis without the whine. Our results confirm that it is the upper harmonics of the natural chuck stimulating the basilar papilla that are responsible for this effect. In addition, our results demonstrate that the final portion of the natural whine stimulating the low-frequency portion of the amphibian papilla between 500 and $430 \mathrm{~Hz}$ plays a similar role. Alone it cannot trigger phonotaxis, but a whine with it is more attractive than one that only stimulates the high and low portions of the amphibian papilla necessary and sufficient for phonotaxis. Because very low-frequency amphibian papilla and high-frequency basilar papilla stimulation do not participate in call recognition per se, but do make calls that are recognized more attractive, there must be a part of the neural circuitry for call analysis that monitors stimulation of both auditory papillae and biases phonotaxis towards calls that occur when it is activated. This part of the neural system appears very permissive with respect to the stimuli it will accept. Our tests and previous studies (R yan $\&$ Rand 1990; $R$ and et al. 1992) indicate very few restrictions on the frequency characteristics of stimuli that enhance call attractiveness. Stimulation of the amphibian papilla anywhere from 900 to $430 \mathrm{~Hz}$, or stimulation of the basilar papilla in any way, will make a call more attractive than one that lacks such stimulation. Therefore, the system that assesses call attractiveness will accept input from the parts of the amphibian papilla involved in call recognition, parts of the amphibian papilla that are not involved in call recognition, and from the basilar papilla.

Although we did not thoroughly investigate variation in the temporal characteristics of the whine and chuck, our results do show that there is some permissiveness in whether the enhancing stimulation occurs before or after the recognition of the call. A whine without the initial $50 \mathrm{~ms}$ is less attractive than one with it even though both will elicit phonotaxis. Because this portion of the whine does not reach the low-frequency portion

Figure 5. Diagram of the way in which spectral cues in the advertisement call are used in recognizing a call (a) and assessing its relative attractiveness (c). The processes are represented separately for illustration purposes only; our data are consistent with, but do not prove, two separate stages of call processing. The basilar papilla (BP), which is tuned to $2100 \mathrm{~Hz}$, and amphibian papilla (A P), which contains receptors for frequencies between 100 and $1200 \mathrm{~Hz}$, are represented in (b). A natural whine stimulates the amphibian papilla from 900 to $430 \mathrm{~Hz}$. Stimulation anywhere between 900 and $560 \mathrm{~Hz}$, followed at least 50 ms later by stimulation between 640 and $500 \mathrm{~Hz}$ in a natural whine is necessary for call recognition, although there is no single frequency in either region that must be stimulated for recognition to occur. T ests with other stimuli suggest that the high-frequency portion might extend to $500 \mathrm{~Hz}$ and the low-frequency portion to $430 \mathrm{~Hz}$. Shaded areas at 900 and $430 \mathrm{~Hz}$ indicate that we do not know the exact high and low cut-off frequencies for this system. A dditional stimulation anywhere in the amphibian papilla from 900 to $430 \mathrm{~Hz}$ or in the basilar papilla makes the call more attractive; the call assessment systems seems to simply sum energy from the different frequency bands. The call-recognition function turns on phonotaxis while the call-assessment function acts as a gain-control mechanism (expressed as preference among calls). Together the systems result in mate choice for a particular call. 
necessary to complete call recognition, and because the whine must last more than $50 \mathrm{~ms}$ to be recognized, that result indicates that highfrequency amphibian papilla stimulation prior to call recognition can enhance the attractiveness of the subsequently recognized call. Our data therefore indicate that the call-assessment portion of the processing network does not wait until call recognition is complete to become active.

We currently know little else about the temporal requirements tying the call-recognition decision to the call-assessment function. There must be some requirement for near simultaneity between the activity in these two systems so that the same individual's call can be evaluated in both domains. We have not yet investigated the limits of that requirement, nor have we determined whether such adornments might occur simultaneously with the key recognition portions of the call and still enhance a call or make it less attractive. R and et al. (1992) presented results suggesting that harmonics added to the whine did not make the whine more attractive. However, it remains unclear why those additions failed to make the call more attractive. An extensive investigation of the temporal constraints on call recognition and enhancement is crucial to understanding fully the potential interactions between the decisions underlying each aspect of call processing.

Our current data cannot determine how separate the mechanisms of call recognition and call assessment are. The data are consistent with the idea (but do not prove) that they are separate, parallel systems in terms of their inputs, and therefore we have presented them as such, with their outputs converging at some point to control phonotaxis towards a call. The first, or callrecognition system, receives input from two specific parts of the amphibian papilla that must be stimulated, in order, beyond a minimal time frame; the second, or call-assessment system, receives input from both the amphibian and basilar papillae without regard to the temporal relationship of the stimulation. The first enables phonotaxis; its activation is necessary and sufficient for that behaviour to be expressed. The output of the second system acts as a gain-control mechanism for the behaviour switched on by the first system, increasing the likelihood of phonotaxis to the particular call that the first system has recognized. A ctivation of this call-assessment system alone will not trigger phonotaxis, but activation of this system in conjunction with the call-recognition system will bias that behaviour to the call that has activated both.

Although we have presented call recognition and assessment as separate decisions, our results indicate that the call itself and the auditory periphery are not cleanly divided into portions for interspecific (call recognition) and intraspecific (call assessment) communication. Our results and previous work (R yan \& R and 1990; R yan et al. 1990) do suggest that in natural calls the basilar papilla, which detects the chuck, is dedicated to intraspecific mate choice. However, the amphibian papilla and the whine it detects are not solely involved in interspecific call discrimination. Adding acoustic adornments that stimulate the amphibian papilla to the minimal call features triggering phonotaxis also makes a call more attractive. The inclusion of the amphibian papilla input in the call-assessment system is a reflection of the extreme permissiveness of this portion of the call-analysis system. To date, our results indicate that signals stimulating any part of the peripheral auditory system will make a call more attractive.

A cross a large sample of species, male signals that are more stimulatory tend to be the signals that females prefer ( $\mathrm{R}$ yan $\&$ K eddy-H ector 1992). Our tests of whine and chuck variants confirm this trend for $P$.pustulosus female choice. M any acoustically impoverished whine variants are recognized as calls and are perfectly adequate to support female phonotaxis. When presented against a natural call in a two-choice test, however, none is as attractive as the full fundamental of a natural whine stimulating a broader range of frequencies. F urthermore, a full whine stimulating only the amphibian papilla is not as attractive as a whine coupled with a chuck, which stimulates both the amphibian and basilar papillae. Our tests substituting tones for chucks further support this idea in that there is a trend for a tone at the best excitatory frequency of the basilar papilla to be preferred to one far away (see also Ryan 1985; $R$ yan et al. 1990). The extreme permissiveness in the assessment portion of the call analyser suggests that calls could evolve any manner of equally effective acoustic adornments surrounding the key call features used for conspecific recognition. Thus, as the sensory exploitation hypothesis (Ryan 1990b) suggests, sexual selection might 
result from males evolving traits that exploit the permissiveness of the receiving system rather than signals and receivers evolving in a tightly coordinated, coevolutionary manner. Limitations on this process may be less imposed by the call-analysis system than by vocal-production mechanisms, energetic considerations, or habitat acoustics.

R ecently, Reeve \& Sherman (1993) have criticized the use of mechanistic explanations in interpreting behavioural characters, in general, and, specifically, the sensory exploitation hypothesis as we have presented it. We had pointed out that basilar papilla tuning in $P$. pustulosus and $P$. coloradorum is similar despite the fact that $P$. coloradorum does not produce chucks and its whine is restricted to the amphibian papillasensitive frequency range. Phylogenetic information argues strongly that the similarity in tuning properties is shared through common descent, and thus the basilar papilla tuning of $P$. pustulosus probably existed prior to the evolution of the chuck ( $R$ yan et al. 1990). R eeve $\&$ Sherman reject this idea, arguing instead that in $P$. coloradorum there might be an adaptive preference for lowpitched calls, and thus the basilar papilla tuning of the two species is similar due to convergent evolution favouring preference for larger males that produce lower-pitched calls. The problem with R eeve $\&$ Sherman's argument is their failure to consider the mechanisms of auditory processing of the whine and chuck discussed by $R$ yan et al. (1990). The amphibian papilla is primarily responsible for processing the whine in both species, and in $\mathrm{P}$. coloradorum little if any of the energy in their whine-like calls falls within the frequency range to which the basilar papilla is sensitive. The tuning of the female's basilar papilla thus has no influence on call recognition or preference in that species. If female $P$. coloradorum were to gain any benefit by choosing male conspecifics with lower-frequency calls, the only call component that could be lowered is the whine. This might influence the tuning of the female's amphibian papilla, but not her basilar papilla as R eeve $\&$ Sherman have argued. This misunderstanding emphasizes how, contrary to the general premise presented in Reeve \& Sherman (1993), understanding adaptation is a multidisciplinary problem requiring the integration of mechanisms, history and current function.

Several authors have argued that recognition systems should be very selective because of the extreme consequences of heterospecific mating (e.g. Dobzhansky 1937; Paterson 1985; Coyne \& Orr 1989). Our results do indicate that call recognition is more selective than the assessment of call attractiveness in its use of spectral information. $\mathrm{N}$ evertheless, call recognition is still fairly permissive. Our results indicate that call recognition requires only some stimulation within a highfrequency region of the amphibian papilla followed by stimulation within a partially overlapping low-frequency amphibian papilla region, and that the frequency sweep must be at least 50 ms long. We do note, however, that there may be additional temporal restrictions on the form of the call that we have not yet tested. The flexibility of the recognition system is no doubt a reflection of the reality of animal communication in which a range of intraspecific variation in vocal production and auditory reception must be accommodated by the recognition system, as must the unpredictable influences of habitat acoustics and heterospecific call interference on the transmitted call.

The flexibility of the recognition system and the permissiveness of the system assessing attractiveness have obvious implications for ideas about the strength of species isolation based on communication signals. Previous studies ( $R$ and \& Ryan 1981; R yan 1985; $R$ yan \& $R$ and 1990; $R$ and et al. 1992) and our results have shown that there are some limits to the type of signals that female $P$. pustulosus will recognize as a conspecific mate attractant. Therefore the call-recognition system will prevent matings with many heterospecifics. Our results show, however, that for $P$. pustulosus there are many variants of the call that will be recognized as signalling an acceptable mate. $M$ any of these variants are never produced by the males of this species. Similarly, our results suggests that there are a large number of ways to make a recognizable call more attractive, and many are ways not normally used by these frogs. It is easily conceivable that individuals could recognize and accept heterospecific calls as long as they do not stray too far from the minimal requirements needed for conspecific call recognition, and may even prefer those calls to conspecific calls if they contain some of the wide range of potential adornments. This in fact occurs in $P$. pustulosus (Ryan \& R and 1993a, c) and it has also been reported in other species (reviewed by $R$ yan $\&$ $\mathrm{K}$ eddy-H ector 1992). G iven our results outlining the decision-making processes of $P$. pustulosus 
and our understanding of the call variation among the many species in this genus ( $R$ yan $\& R$ and $1993 a, c)$, this group of vertebrates could provide a model for understanding potential heterospecific social interactions as well as the basic processes underlying the evolution of divergent communication signals.

\section{ACKNOWLEDGMENTS}

We thank the staff of the Smithsonian Tropical R esearch Institute for providing the assistance necessary for the completion of this research. We especially appreciate the assistance of $F$. Bolanos, $M$. D antzker, J. Ellingson, D. Lombiedo, K. M ills, P. M onsivais, G. M ora, G. R osenthal and $M$. Sasa with the phonotaxis experiments. We also thank H. C. Gerhardt for comments on the manuscript and S. Douglas for her work on the illustrations. This research was supported by the Smithsonian Institution Scholarly Studies Program.

\section{REFERE NCES}

Basolo, A. 1990. Female preference predates the evolution of sword in swordtails. Science, 250, 808-810.

Burley, N. 1985. The organization of behavior and the evolution of sexually selected traits. In: A vian M onogamy. Ornithological M onographs N 0. 37 (Ed. by P. A. Gowaty \& D. W. M ock), pp. 22-44. W ashington, DC: A merican Ornithologists' U nion.

Christy, J. H . 1988. Pillar functions in fiddler crabs U ca beebei. II. Competitive courtship signalling. E thology, 78, 113-128.

Coyne, J. A . \& Orr, H. A . 1989. Patterns of speciation in D rosophila. Evolution, 43, 362-381.

D obzhansky, T. 1937. Genetics and the O rigin of Species. N ew Y ork: Columbia U niversity Press.

Gerhardt, H. C. 1988. A coustic properties used in call recognition by frogs and toads. In: The Evolution of the A mphibian A uditory System (Ed. by B. Fritzsch, M. J. Ryan, W. Wilczynski, T. E. H etherington \& W. Walkowiak), pp. 455-483. N ew Y ork: J ohn W iley.

Lewis, E. R. \& Lombard, R. E. 1988. The amphibian inner ear. In: The Evolution of the Amphibian A uditory System (Ed. by B. F ritzsch, M. J. R yan, W. Wilczynski, T. E. H etherington \& W. Walkowiak), pp. 93-124. N ew Y ork: John Wiley.

Littlejohn, M . J . 1981. R eproductive isolation: a critical review. In: Essays in $\mathrm{H}$ onor of $M$. J. D. W hite (Ed. by W. R. Atchley \& D. S. Woodruff), pp. 298-334. Cambridge: Cambridge U niversity Press.

Littlejohn, M. J. 1988. F rog calls and speciation: the retrograde evolution of homogametic acoustic signal- ling systems in hybrid zones. In: The Evolution of the A mphibian A uditory System (E d. by B. F ritzsch, M. J . Ryan, W. Wilczynski, T. E. Hetherington \& W. Walkowiak), pp. 613-635. N ew Y ork: John Wiley.

M ayr, E. 1963. A nimal Species and Evolution. Cambridge, M assachusetts: Harvard U niversity Press.

Paterson, H. E. H. 1985. The recognition concept of species. In: Species and Speciation ( $E d$. by $E$. V rba), pp. 21-29. Pretoria: Transvaal M useum M onographs.

Proctor, H. C. 1991. Courtship in the water mite $\mathrm{N}$ eumania papillator: males capitalize on female adaptations for predation. A nim. Behav., 42, 589-598.

Proctor, H. C. 1993. Sensory exploitation and the evolution of male mating behaviour: a cladistic test using water mites (A cari: Parasitengona). A nim. B ehav., 44, 745- 752.

$R$ and, A. S. 1988. An overview of anuran acoustic communication. In: The Evolution of the Amphibian A uditory System (Ed. by B. F ritzsch, M. J. R yan, W. Wilczynski, T. E. H etherington \& W. Walkowiak), pp. 415-431. N ew Y ork: J ohn Wiley.

R and, A. S. \& Ryan, M. J. 1981. The adaptive significance of a complex vocal repertoire in a neotropical frog. Z. Tierpsychol., 57, 209-214.

R and, A. S., R yan, M . J . \& W ilczynski, W. 1992. Signal redundancy and receiver permissiveness in acoustic mate recognition by the túngara frog, $\mathrm{P}$ hysalaemus pustulosus. A m. Z ool., 32, 81-90.

R eeve, H. K . \& Sherman, P. W. 1993. A daptation and the goals of evolutionary research. Q. R ev. Biol., 68, $1-32$.

Rose, G. J., Zelick, R. \& Rand, A. S. 1988. A uditory processing of temporal information in a $\mathrm{N}$ eotropical frog is independent of signal intensity. Ethology, 77, 330-336.

R yan, M. J . 1980. F emale mate choice in a neotropical frog. Science, 209, 523-525.

Ryan, M. J. 1983a. F requency modulated calls and species recognition in a neotropical frog. J. comp. Physiol., 150, 217-221.

R yan, M . J . 1983b. Sexual selection and communication in a neotropical frog, Physalaemus pustulosus. Evolution, 37, 261-172.

R yan, M . J. 1985. The Túngara Frog, A Study in Sexual Selection and Communication. Chicago: U niversity of Chicago Press.

R yan, M. J . 1990a. Signals, species and sexual selection. A m. Scient., 78, 46-52.

Ryan, M. J. 1990b. Sexual selection, sensory systems, and sensory exploitation. Oxf. Surv. evol. Biol., 7, 157-195.

Ryan, M. J., Fox, J. H. \& Wilczynski, W. 1990. Sexual selection for sensory exploitation in the frog Physalaemus pustulosus. Nature, Lond., 343, 66-67.

Ryan, M. J. \& K eddy-H ector, A. 1992. Directional patterns of female mate choice and the role of sensory biases. A m. N at., 139, S4-S35.

Ryan, M. J., Perrill, S. A. \& Wilczynski, W. 1992. Auditory tuning and call frequency predict population-based mating preferences in the cricket frog, A cris crepitans. A m. N at., 139, 1370-1383. 
Ryan, M. J . \& R and, A. S. 1990. The sensory basis of sexual selection for complex calls in the túngara frog, P hysalaemus pustulosus (sexual selection for sensory exploitation). E volution, 44, 305-314.

R yan, M . J . \& R and, A. S. 1993a. Phylogenetic patterns of behavioral mate recognition systems in the Physalaemus pustulosus species group (A nura: L eptodactylidae): the role of ancestral and derived characters and sensory exploitation. In: Evolutionary Patterns and Processes ( $E d$. by $D$. Edwards \& D. Lees), pp. 251-267. Linnean Society Symposium Series N o. 14. London: A cademic Press.

Ryan, M. J . \& R and, A. S. 1993b. Sexual selection and signal evolution: the ghost of biases past. Phil. Trans. R. Soc. Ser. B, 340, 187-195.

R yan, M. J. \& R and, A. S. 1993c. Species recognition and sexual selection as a unitary problem in animal communication. Evolution, 47, 647-657.

Ryan, M. J. \& Wagner, W. E. 1987. A symmetries in mating preferences between species: female swordtails prefer heterospecific mates. Science, 236, 595-597.

Searcy, W. A. 1992. Song repertoire and mate choice in birds. A m. Z ool., 32, 71-80.
Wells, K. D. 1977. The social behavior of anuran amphibians. A nim. Behav., 25, 666-693.

West-Eberhard, M. J. 1983. Sexual selection, social competition and speciation. Q. Rev. Biol., 58, 155-183.

Wilczynski, W. 1992. The nervous system. In: Environmental Physiology of the Amphibians ( $E d$. by M. E. F eder \& W. Bruggren), pp. 9-39. Chicago: U niversity of Chicago Press.

Wilczynski, W. \& Capranica, R. R. 1984. The auditory system of anuran amphibians. Prog. Neurobiol., 22, $1-38$.

Zakon, H. H.\& Wilczynski, W. 1988. The physiology of the anuran eighth nerve. In: The Evolution of the A mphibian A uditory System (Ed. by B. F ritzsch, M. J . Ryan, W. Wilczynski, T. E. Hetherington \& W. Walkowiak), pp. 125-155. N ew Y ork: J ohn Wiley.

Zelick, R., Rose, G. \& R and, A. S. 1991. Differential response to frequency modulation rate and direction by the $\mathrm{N}$ eotropical frog, Physalaemus pustulosus. A nim. B ehav., 42, 413-421. 